\title{
Some criteria for concave conformal mappings
}

\section{Zhi-Gang Wang* and Ming-Liang Li}

${ }^{*}$ Correspondence: wangmath@163.com

School of Mathematics and Computing Science, Hunan First Normal University, Changsha, Hunan 410205, China

\section{Abstract \\ The main purpose of this paper is to derive some criteria for concave conformal mappings.}

MSC: Primary 30C55

Keywords: concave mapping; meromorphic function; Jack's lemma

\section{Introduction}

A conformal, meromorphic function $f$ on the punctured unit disk

$$
\mathbb{U}^{*}:=\{z \in \mathbb{C}: 0<|z|<1\}=: \mathbb{U} \backslash\{0\}
$$

is said to be a concave mapping if $f\left(\mathbb{U}^{*}\right)$ is the complement of a compact, convex set.

Let $\Sigma$ denote the class of analytic functions of the form

$$
f(z)=\frac{1}{z}+\sum_{k=0}^{\infty} b_{k} z^{k} \quad\left(z \in \mathbb{U}^{*}\right)
$$

then the necessary and sufficient condition for $f$ to be a concave mapping is

$$
1+\Re\left(\frac{z f^{\prime \prime}(z)}{f^{\prime}(z)}\right)<0 \quad(z \in \mathbb{U})
$$

where

$$
\frac{z f^{\prime \prime}(z)}{f^{\prime}(z)}=-2-2 b_{1} z^{2}-6 b_{2} z^{3}-\left(12 b_{3}+2 b_{1}^{2}\right) z^{4}-\cdots .
$$

Recently, Bhowmik et al. [1], Chuaqui et al. [2], Ibrahim and Sokół [3] derived some interesting properties of concave conformal mappings. In this paper, we aim at proving several criteria for the function $f \in \Sigma$ to be a concave mapping.

To prove our main results, we need the following two lemmas.

Lemma 1.1 (Jack's lemma [4]) Let $h(z)=a_{n} z^{n}+a_{n+1} z^{n+1}+\cdots$ be a non-constant analytic function in $\mathbb{U}$. If $|h(z)|$ attains its maximum value on the circle $|z|=r<1$, then

$$
z_{0} h^{\prime}\left(z_{0}\right)=k h\left(z_{0}\right) \text {, }
$$

where $k$ is a real number with $k \geq n$.

\section{Springer}

(c) 2015 Wang and Li; licensee Springer. This is an Open Access article distributed under the terms of the Creative Commons Attribution License (http://creativecommons.org/licenses/by/4.0), which permits unrestricted use, distribution, and reproduction in any medium, provided the original work is properly credited. 
Lemma 1.2 (See [5]) Let $\Omega$ be a set in the complex plane $\mathbb{C}$ and suppose that $\Phi$ is a mapping from $\mathbb{C}^{2} \times \mathbb{U}$ to $\mathbb{C}$ which satisfies $\Phi(i x, y ; z) \notin \Omega$ for $z \in \mathbb{U}$ and for all real $x, y$ such that $y \leq-\frac{1+x^{2}}{2}$. If the function $p(z)=1+c_{1} z+c_{2} z^{2}+\cdots$ is analytic in $\mathbb{U}$ and $\Phi\left(p(z), z p^{\prime}(z) ; z\right) \in \Omega$ for all $z \in \mathbb{U}$, then $\Re(p(z))>0$.

\section{Main results}

We first give the following result.

Theorem 2.1 Suppose that $f \in \Sigma$ with $\left(z f^{\prime}(z)\right)^{\prime} \neq 0$. If $f$ satisfies the condition

$$
\left|\frac{z f^{\prime \prime}(z)}{f^{\prime}(z)}-\frac{z\left(2 f^{\prime \prime}(z)+z f^{\prime \prime \prime}(z)\right)}{f^{\prime}(z)+z f^{\prime \prime}(z)}\right|<\lambda \quad\left(0<\lambda \leq \frac{1}{2}\right)
$$

then $f$ is concave in $\mathbb{U}^{*}$.

Proof Assume that

$$
\phi(z):=\frac{(1-\lambda) \frac{f^{\prime}(z)}{f^{\prime}(z)+z f^{\prime \prime}(z)}+1}{\lambda}-1 \quad\left(0<\lambda \leq \frac{1}{2} ; z \in \mathbb{U}\right) .
$$

Then the function $\phi$ is analytic in $\mathbb{U}$ with $\phi(0)=0$. From (2.2), we know that

$$
\frac{f^{\prime}(z)}{f^{\prime}(z)+z f^{\prime \prime}(z)}=\frac{\lambda \phi(z)+\lambda-1}{1-\lambda} \text {. }
$$

By differentiating both sides of (2.3) with respect to $z$ logarithmically, we get

$$
\frac{z f^{\prime \prime}(z)}{f^{\prime}(z)}-\frac{z\left(2 f^{\prime \prime}(z)+z f^{\prime \prime \prime}(z)\right)}{f^{\prime}(z)+z f^{\prime \prime}(z)}=\frac{\lambda z \phi^{\prime}(z)}{\lambda \phi(z)+\lambda-1}
$$

From (2.1) and (2.4), we find that

$$
\left|\frac{z f^{\prime \prime}(z)}{f^{\prime}(z)}-\frac{z\left(2 f^{\prime \prime}(z)+z f^{\prime \prime \prime}(z)\right)}{f^{\prime}(z)+z f^{\prime \prime}(z)}\right|=\lambda\left|\frac{\lambda z \phi^{\prime}(z)}{\lambda \phi(z)+\lambda-1}\right|<\lambda
$$

Now, we can claim that $|\phi(z)|<1$. If not, there exists a point $z_{0} \in \mathbb{U}$ such that

$$
\max _{|z| \leq\left|z_{0}\right|}|\phi(z)|=\left|\phi\left(z_{0}\right)\right|=1
$$

By Lemma 1.1, we know that

$$
z_{0} \phi^{\prime}\left(z_{0}\right)=k \phi\left(z_{0}\right)=k e^{i \theta} \quad(0 \leq \theta<2 \pi ; k \geq 1) .
$$

For $z=z_{0}$, we find from (2.4) and (2.6) that

$$
\left|\frac{z_{0} f^{\prime \prime}\left(z_{0}\right)}{f^{\prime}\left(z_{0}\right)}-\frac{z_{0}\left(2 f^{\prime \prime}\left(z_{0}\right)+z_{0} f^{\prime \prime \prime}\left(z_{0}\right)\right)}{f^{\prime}\left(z_{0}\right)+z_{0} f^{\prime \prime}\left(z_{0}\right)}\right|=\lambda\left|\frac{k}{\lambda+(\lambda-1) e^{-i \theta}}\right| \geq \lambda .
$$


But (2.7) contradicts (2.5). Thus, we deduce that $|\phi(z)|<1$, which implies that

$$
\left|\frac{(1-\lambda) \frac{f^{\prime}(z)}{f^{\prime}(z)+z f^{\prime \prime}(z)}+1}{\lambda}-1\right|<1
$$

or equivalently,

$$
\left|\frac{f^{\prime}(z)}{f^{\prime}(z)+z f^{\prime \prime}(z)}+1\right|<\frac{\lambda}{1-\lambda} .
$$

From (2.9), we get

$$
\Re\left(1+\frac{z f^{\prime \prime}(z)}{f^{\prime}(z)}\right)<\lambda-1<0 \quad\left(0<\lambda \leq \frac{1}{2}\right),
$$

which shows that the function $f$ is concave in $\mathbb{U}^{*}$.

Theorem 2.2 Suppose that $f \in \Sigma$ with $f^{\prime}(z) \neq 0$. Iff satisfies the inequality

$$
\Re\left(\frac{z\left[\left(f^{\prime \prime}(z)+z f^{\prime \prime \prime}(z)\right) f^{\prime}(z)-z\left(f^{\prime \prime}(z)\right)^{2}\right]}{f^{\prime}(z)\left(z f^{\prime \prime}(z)+3 f^{\prime}(z)\right)}\right)<1,
$$

then $f$ is concave in $\mathbb{U}^{*}$.

Proof Define the function $\varphi(z)$ by

$$
\varphi(z):=\frac{z f^{\prime \prime}(z)}{f^{\prime}(z)}+2 \quad(z \in \mathbb{U})
$$

It is easy to see that

$$
\varphi(z)=-2 b_{1} z^{2}-6 b_{2} z^{3}-\left(12 b_{3}+2 b_{1}^{2}\right) z^{4}-\cdots
$$

is analytic in $\mathbb{U}$ with $\varphi(0)=\varphi^{\prime}(0)=0$. From (2.11), we obtain

$$
\frac{z f^{\prime \prime}(z)}{f^{\prime}(z)}+3=1+\varphi(z) \quad(z \in \mathbb{U})
$$

Taking logarithmical derivatives of both sides of (2.12) with respect to $z$, we get

$$
\frac{z\left[\left(f^{\prime \prime}(z)+z f^{\prime \prime \prime}(z)\right) f^{\prime}(z)-z\left(f^{\prime \prime}(z)\right)^{2}\right]}{f^{\prime}(z)\left(z f^{\prime \prime}(z)+3 f^{\prime}(z)\right)}=\frac{z \varphi^{\prime}(z)}{1+\varphi(z)}
$$

We now show that $|\varphi(z)|<1$. If not, there exists a point $z_{0} \in \mathbb{U}$ such that

$$
\max _{|z| \leq\left|z_{0}\right|}|\varphi(z)|=\left|\varphi\left(z_{0}\right)\right|=1
$$

By Jack's lemma, we know that

$$
z_{0} \varphi^{\prime}\left(z_{0}\right)=k \varphi\left(z_{0}\right)=k e^{i \theta} \quad(0 \leq \theta<2 \pi ; k \geq 2) .
$$


For $z=z_{0}$, we have

$$
\begin{gathered}
\Re\left(\frac{z_{0}\left[\left(f^{\prime \prime}\left(z_{0}\right)+z_{0} f^{\prime \prime \prime}\left(z_{0}\right)\right) f^{\prime}\left(z_{0}\right)-z_{0}\left(f^{\prime \prime}\left(z_{0}\right)\right)^{2}\right]}{f^{\prime}\left(z_{0}\right)\left(z_{0} f^{\prime \prime}\left(z_{0}\right)+3 f^{\prime}\left(z_{0}\right)\right)}\right) \\
\quad=\Re\left(\frac{z_{0} \varphi^{\prime}\left(z_{0}\right)}{1+\varphi\left(z_{0}\right)}\right)=\mathfrak{R}\left(\frac{k e^{i \theta}}{1+e^{i \theta}}\right) \geq \frac{k}{2} \geq 1 .
\end{gathered}
$$

But (2.15) is a contradiction to condition (2.10), which implies that $|\varphi(z)|<1$. Consequently, we deduce from (2.11) that

$$
\Re\left(1+\frac{z f^{\prime \prime}(z)}{f^{\prime}(z)}\right)=\mathfrak{R}(\varphi(z))-1 \leq|\varphi(z)|-1<0,
$$

which implies that $f$ is concave in $\mathbb{U}^{*}$.

Theorem 2.3 Suppose that $f \in \Sigma$ with $f^{\prime}(z) \neq 0$. Iff satisfies the condition

$$
\Re\left(\frac{z f^{\prime}(z)}{\left(z f^{\prime}(z)\right)^{\prime}}\left(\frac{\left(z f^{\prime}(z)\right)^{\prime}}{f^{\prime}(z)}\right)^{\prime}\right)> \begin{cases}\frac{\delta}{2(\delta-1)} & \left(0 \leqq \delta \leqq \frac{1}{2}\right) \\ \frac{\delta-1}{2 \delta} & \left(\frac{1}{2} \leqq \delta<1\right)\end{cases}
$$

then $f$ is concave in $\mathbb{U}^{*}$.

Proof Suppose that

$$
\psi(z)=\frac{-\frac{z f^{\prime \prime}(z)}{f^{\prime}(z)}-1-\delta}{1-\delta} \quad(0 \leq \delta<1 ; z \in \mathbb{U})
$$

Then $\psi$ is analytic in $\mathbb{U}$. From (2.17), we find that

$$
\frac{z f^{\prime}(z)}{\left(z f^{\prime}(z)\right)^{\prime}}\left(\frac{\left(z f^{\prime}(z)\right)^{\prime}}{f^{\prime}(z)}\right)^{\prime}=\frac{(1-\delta) z \psi^{\prime}(z)}{\delta+(1-\delta) \psi(z)}=\Phi\left(\psi(z), z \psi^{\prime}(z) ; z\right)
$$

where

$$
\Phi(r, s ; t)=\frac{(1-\delta) s}{\delta+(1-\delta) r}
$$

For the real numbers $x$ and $y$ satisfying the condition $y \leq-\frac{1+x^{2}}{2}$, we know that

$$
\begin{aligned}
\Re(\Phi(i x, y ; z)) & =\frac{(1-\delta) \delta y}{\delta^{2}+(1-\delta)^{2} x^{2}} \\
& \leq-\frac{(1-\delta) \delta}{2} \cdot \frac{1+x^{2}}{\delta^{2}+(1-\delta)^{2} x^{2}} \\
& \leq \begin{cases}\frac{\delta}{2(\delta-1)} & \left(0 \leqq \delta \leqq \frac{1}{2}\right), \\
\frac{\delta-1}{2 \delta} & \left(\frac{1}{2} \leqq \delta<1\right) .\end{cases}
\end{aligned}
$$

Now, we take

$$
\Omega=\left\{\xi: \Re(\xi)>\left\{\begin{array}{ll}
\frac{\delta}{2(\delta-1)} & \left(0 \leqq \delta \leqq \frac{1}{2}\right) \\
\frac{\delta-1}{2 \delta} & \left(\frac{1}{2} \leqq \delta<1\right)
\end{array}\right\}\right.
$$


then $\Phi(i x, y ; z) \notin \Omega$ for all real $x, y$ such that $y \leq-\frac{1+x^{2}}{2}$. Furthermore, by virtue of (2.16), we know that $\Phi\left(\psi(z), z \psi^{\prime}(z) ; z\right) \in \Omega$. Thus, by Lemma 1.2, we get $\Re(\psi(z))>0$, which shows that $f$ is concave in $\mathbb{U}^{*}$.

Finally, we correct an error of Theorem 2.1 in [3], the condition

$$
\Re\left(\frac{z f^{\prime \prime \prime}(z)}{f^{\prime \prime}(z)}\right)<0 \quad(z \in \mathbb{U})
$$

in it should be changed into

$$
\Re\left(\frac{z f^{\prime \prime \prime}(z)}{f^{\prime \prime}(z)}\right)>-3 \quad(z \in \mathbb{U})
$$

Theorem 2.4 Suppose that $f \in \Sigma$ with $f^{\prime}(z) \neq 0$. Iff satisfies the inequality

$$
\Re\left(\frac{z f^{\prime \prime \prime}(z)}{f^{\prime \prime}(z)}\right)>-3 \quad(z \in \mathbb{U})
$$

then $f$ is concave in $\mathbb{U}^{*}$.

Proof Define the function $\omega(z)$ by

$$
-1-\frac{z f^{\prime \prime}(z)}{f^{\prime}(z)}=\frac{1+\omega(z)}{1-\omega(z)}
$$

Then $\omega$ is analytic in $\mathbb{U}$ with $\omega(0)=\omega^{\prime}(0)=0$. From (2.21), we get

$$
\frac{z f^{\prime \prime}(z)}{f^{\prime}(z)}=\frac{-2}{1-\omega(z)}
$$

Differentiating both sides of (2.22) logarithmically, we get

$$
\frac{z f^{\prime \prime \prime}(z)}{f^{\prime \prime}(z)}=\frac{z \omega^{\prime}(z)}{1-\omega(z)}+\frac{z f^{\prime \prime}(z)}{f^{\prime}(z)}-1
$$

Now, we show that $|\omega(z)|<1$. If not, there exists a point $z_{0} \in \mathbb{U}$ such that

$$
\max _{|z| \leq\left|z_{0}\right|}|\omega(z)|=\left|\omega\left(z_{0}\right)\right|=1 .
$$

By Jack's lemma, we know that

$$
\begin{aligned}
\Re\left(\frac{z_{0} f^{\prime \prime \prime}\left(z_{0}\right)}{f^{\prime \prime}\left(z_{0}\right)}\right) & =\Re\left(\frac{(k+1) \omega\left(z_{0}\right)-3}{1-\omega\left(z_{0}\right)}\right) \\
& =\Re\left(\frac{(k+1)(\cos \theta+i \sin \theta)-3}{1-\cos \theta-i \sin \theta}\right) \\
& =\frac{(k+4) \cos \theta-(k+4)}{(1-\cos \theta)^{2}+\sin ^{2} \theta} \\
& =\frac{(k+4)(\cos \theta-1)}{(1-\cos \theta)^{2}+\sin ^{2} \theta}
\end{aligned}
$$




$$
\begin{aligned}
& =-\frac{k+4}{2} \\
& \leq-3
\end{aligned}
$$

where $k \geq 2$, but this contradicts (2.20), which implies that $|\omega(z)|<1$. Thus, $f$ is concave in $\mathbb{U}^{*}$.

\section{Competing interests}

The authors declare that they have no competing interests.

\section{Authors' contributions}

All authors completed the paper together. All authors read and approved the final manuscript.

\section{Acknowledgements}

The present investigation was supported by the National Natural Science Foundation under Grant Nos. 11301008 and 11226088, the Aid Program for Science and Technology Innovative Research Team in Higher Educational Institution of Hunan Province, the Foundation of Educational Committee of Henan Province under Grant No. 15A1 1006. The authors would like to thank the referees for their valuable comments and suggestions which essentially improved the quality of this paper.

Received: 25 February 2015 Accepted: 24 March 2015 Published online: 04 April 2015

\section{References}

1. Bhowmik, B, Ponnusamy, S, Wirths, K-J: Concave functions, Blaschke products, and polygonal mappings. Sib. Math. J. 50, 609-615 (2009)

2. Chuaqui, M, Duren, P, Osgood, B: Concave conformal mappings and pre-vertices of Schwarz-Christoffel mappings. Proc. Am. Math. Soc. 140, 3495-3505 (2012)

3. Ibrahim, RW, Sokół, J: A geometric property for a class of meromorphic analytic functions. J. Inequal. Appl. 2014, 120 (2014)

4. Jack, IS: Functions starlike and convex of order $\alpha$. J. Lond. Math. Soc. 3, 469-474 (1971)

5. Miller, SS, Mocanu, PT: Differential subordinations and inequalities in the complex plane. J. Differ. Equ. 67, 199-211 (1987)

\section{Submit your manuscript to a SpringerOpen ${ }^{\circ}$ journal and benefit from:}

- Convenient online submission

- Rigorous peer review

Immediate publication on acceptance

- Open access: articles freely available online

- High visibility within the field

- Retaining the copyright to your article 